\title{
TTR
}

Traduction, terminologie, re?daction

\section{Michel Ballard. Claude-Gaspar Bachet de Méziriac, « De la traduction » [1635], Artois Presse Université, 1998.}

\section{Bruno Garnier}

Volume 13, numéro 1, 1er semestre 2000

Idéologie et traduction

Ideology and Translation

URI : https://id.erudit.org/iderudit/037399ar

DOI : https://doi.org/10.7202/037399ar

Aller au sommaire du numéro

\section{Éditeur(s)}

Association canadienne de traductologie

ISSN

0835-8443 (imprimé)

1708-2188 (numérique)

Découvrir la revue

Citer ce compte rendu

Garnier, B. (2000). Compte rendu de [Michel Ballard. Claude-Gaspar Bachet de Méziriac, « De la traduction » [1635], Artois Presse Université, 1998.] TTR, 13(1), 193-195. https://doi.org/10.7202/037399ar

Tous droits réservés @ C TTR: traduction, terminologie, rédaction — Les auteurs, 2000
Ce document est protégé par la loi sur le droit d'auteur. L'utilisation des services d'Érudit (y compris la reproduction) est assujettie à sa politique d'utilisation que vous pouvez consulter en ligne.

https://apropos.erudit.org/fr/usagers/politique-dutilisation/ 


\section{COMPTES RENDUS}

\section{Michel Ballard. Claude-Gaspar Bachet de Méziriac, «De la traduction » [1635], Artois Presse Université, 1998.}

Le discours de Méziriac sur la traduction est l'un des grands textes méconnus souvent mentionnés mais plus rarement commentés, sans doute en raison de sa situation dans l'histoire, à une distance presque égale des grands débats sur la traduction de la deuxième moitié du XVI ${ }^{e}$ siècle, et des querelles de la fin du XVII siècle qui verront la remise en cause des belles infidèles. L'étude proposée par Michel Ballard en introduction à la réédition du discours « De la traduction » de 1635 permet de comprendre l'apport de Méziriac à la pensée de son temps, dont l'importance a été certainement sous-estimée. Plus que d'une simple réédition, c'est donc d'une redécouverte de première importance qu'il faut parler ici.

Michel Ballard nous présente d'abord l'homme. Claude-Gaspar Bachet, futur seigneur de Méziriac, fut un enfant prodige, né poète. Orienté d'abord dans la voie des lettres par son frère aîné, il reçut sa première éducation savante chez les Jésuites, qu'il quitta à vingt-deux ans. Débute alors une période de voyages, en Italie, à Paris, au cours de laquelle il complète sa formation intellectuelle. Sa prodigieuse mémoire lui permet d'apprendre le latin, le grec, l'hébreu, l'italien et l'espagnol, et il acquiert assez de réputation pour se voir proposer de devenir précepteur du jeune Louis XIII, charge prestigieuse qu'il refuse cependant pour se consacrer pleinement à ses travaux.

Michel Ballard s'attache alors à l'édition assez inattendue des travaux du mathématicien Diophante d'Alexandrie (II siècle après JésusChrist) et surtout à la méthode employée par Méziriac : établissement du texte par la confrontation des leçons manuscrites et correction d'une ancienne traduction latine. "Celui qui allait se permettre de critiquer Amyot, note Michel Ballard, n'était pas un amateur ". Peu après, cet historien des mathématiques que Descartes tenait en haute estime se tourne vers la poésie en publiant une imitation d'Ovide. Le point important est ici la séparation entre les fonctions du philologue appliqué à produire l'édition bilingue d'un ouvrage de mathématiques et celle du poète imitant librement un auteur latin. On verra plus tard quelle direction prendront ces deux manières de transformer les textes étrangers en 
français dans les options théoriques retenues par Méziriac dans son discours sur la traduction.

L'élection de Méziriac à l'Académie Française en 1634 est naturellement le fruit de ces travaux, auxquels il faut ajouter des Commentaires sur Plutarque, une Vie d'Ésope et plusieurs ouvrages de didactique et de piété. L'Académie venait d'être constituée officiellement par Richelieu, et l'on décida, en 1635, que chacun devrait faire un discours à tour de rôle. Celui de Méziriac intitulé " De la traduction " est donc l'un des tout premiers qui fût lu à l'Académie; la maladie l'empêcha de le faire lui-même, et c'est Vaugelas qui s'en chargea. Bachet de Méziriac devait mourir quelques années plus tard, en 1638, et son discours ne fut imprimé qu'en 1715 : c'est l'édition que Michel Ballard a reproduite dans son ouvrage.

Michel Ballard nous livre ensuite une étude du discours de Méziriac, qui commence par un panorama de l'histoire de la traduction depuis la fin du Moyen Âge. Ce rappel fournit une vigoureuse synthèse des options théoriques antérieures qui fondent l'originalité des conceptions de Méziriac. Michel Ballard démontre la dimension novatrice de ce discours qui défend la fidélité au texte source à contre-courant de son temps. En s'attaquant à Amyot, la figure emblématique du grand traducteur français, Méziriac restaurait l'interdiction faite par du Bellay au traducteur de se prendre pour un auteur et de s'arroger le droit à l'invention. Méziriac s'est attaché à redresser les infidélités d'Amyot au texte de Plutarque en un temps où les préceptes de Malherbe faisaient obligation à tout écrivain d'être d'abord fidèle aux canons de l'élégance française.

Toutefois la position méthodologique de Méziriac ne le situe pas entièrement du côté de du Bellay. L'originalité de Méziriac réside selon Michel Ballard, en ce qu'il « ne prend pas parti selon les termes de l'ancienne dichotomie. C'est au nom du sens et de son rapport aux formes qu'il pose des critères de jugement ". Précurseur de la traductologie, Méziriac analyse la pratique de la traduction en proposant une classification raisonnée des erreurs. Ajouts ou retraits opérés par la traduction ne sont pas rapportés à un modèle idéal de la traduction, mais analysés comme des variations qu'il convient de réguler en leur fixant des limites. Michel Ballard souligne ici avec raison qu'on doit se garder d'opposer cet attachement au sens à l'efficacité du texte cible au nom 
d'une théorie plus ou moins formalisée de la réception, et rejeter alors l'analyse de Méziriac du côté de la vaine minutie. La critique de la traduction est un instrument destiné à mesurer la distance du texte source au texte cible, à la contrôler. Elle n'impose pas une norme.

Cela dit, en mettant l'accent sur les rapports de la traduction à son original, Méziriac annonce Huet et jette les bases d'une éthique de la traduction, qui, quelles que soient ses ambitions, ne peut se désintéresser complètement de la relation à sa source.

Cette riche introduction, complétée par une bibliographie des cuvres de Méziriac et des références anciennes et modernes sur cet auteur, met le traité « De la traduction » en perspective, au regard du passé mais aussi de sa postérité, et justifie amplement la réédition d'un ouvrage dans lequel il faut voir, selon l'expression de Michel Ballard, une " contribution à la traductologie », et le travail d'un précurseur.

On soulignera enfin la qualité du fac-similé conforme à l'édition de 1715, et on saura gré à Michel Ballard d'avoir rendu à Claude-Gaspar Bachet de Méziriac la place qui lui revient dans l'histoire de la traductologie.

Bruno Garnier Institut Universitaire de Formation des Maîtres de Corse 